\title{
Research on Alpine Landscape Development: From Research to Policy
}

Author(s): Paul Messerli

Source: Mountain Research and Development, 28(2):128-131. 2008.

Published By: International Mountain Society

DOI: http://dx.doi.org/10.1659/mrd.0994

URL: http://www.bioone.org/doi/full/10.1659/mrd.0994

BioOne (www.bioone.org) is a nonprofit, online aggregation of core research in the biological, ecological, and environmental sciences. BioOne provides a sustainable online platform for over 170 journals and books published by nonprofit societies, associations, museums, institutions, and presses.

Your use of this PDF, the BioOne Web site, and all posted and associated content indicates your acceptance of BioOne's Terms of Use, available at www.bioone.org/page/terms_of_use.

Usage of BioOne content is strictly limited to personal, educational, and non-commercial use. Commercial inquiries or rights and permissions requests should be directed to the individual publisher as copyright holder.

BioOne sees sustainable scholarly publishing as an inherently collaborative enterprise connecting authors, nonprofit publishers, academic institutions, research libraries, and research funders in the common goal of maximizing access to critical research. 


\section{Research on Alpine Landscape Development: From Research to Pollicy}

Swiss National Research Programs (NRPs) are usually geared to addressing issues of major societal concern. In so doing these programs produce different kinds of knowledge: analytical knowledge necessary for revealing the driving forces, conflicting interests and institutional settings that govern the processes under scrutiny; target knowledge oriented towards revealing the directions in which the processes should be guided; and action knowledge that informs about the means by which this can best be achieved. Analytical knowledge answers the questions "what is the problem?" and "what causes it?" while target knowledge helps to define "what is our vision for the future?" and action knowledge deals with "how can we solve the problem?" Production of these 3 different types of knowledge is usually linked in an iterative process in the course of the research supported in an NRP.

\section{From research to policy}

The present paper aims to outline the conceptual framework of the Swiss NRP "Landscapes and Habitats of the Alps" (NRP48) - the program within which the articles in this issue were produced. It is intended to act as an interface between the Research and Development sections of this special issue of $M R D$, ie between knowledge production presented in the following papers, and the designing and implementation of measures for action presented in the Development section. It shows how the perspective of historical landscape research in Switzerland was translated into a research perspective, building on the hypothesis that a new form of governance of landscape development is needed. This evolution is highlighted in 4 steps, each illustrated by a fig- ure pointing out key conceptual aspects taken up in the 4 papers that follow. A second purpose of this paper is to provide a framework for the different approaches to a new governance of landscape development presented in the articles in the Development section.

The NRP48 was established in response to a growing public and political concern about:

- A decrease in the capacity to control landscape development due to a lack of human resources to maintain traditional cultural landscapes;

- A general conviction in Switzerland that landscape is one of the country's primary assets, especially in Alpine areas, where development conditions are particularly challenging;

- The existence of a multitude of policies related to land use, infrastructure and conservation, without common responsibility. (For more information on the NRP48, see www.nfp48.ch)

\section{1) Alpine landscapes and changing societal claims over the past $\mathbf{5 0}$ years}

Landscapes in the Alps have always been multifunctional; however, the focus on specific functions has changed over time, especially in the recent past, leading to a corresponding shift of focus in research and policy (Figure 1). From a historical perspective, farming societies conceived of landscape primarily as a pool of natural resources to live in and live on: landscape was a place for living and an economic space, and was shaped into a cultural landscape with a heritage value for its inhabitants.

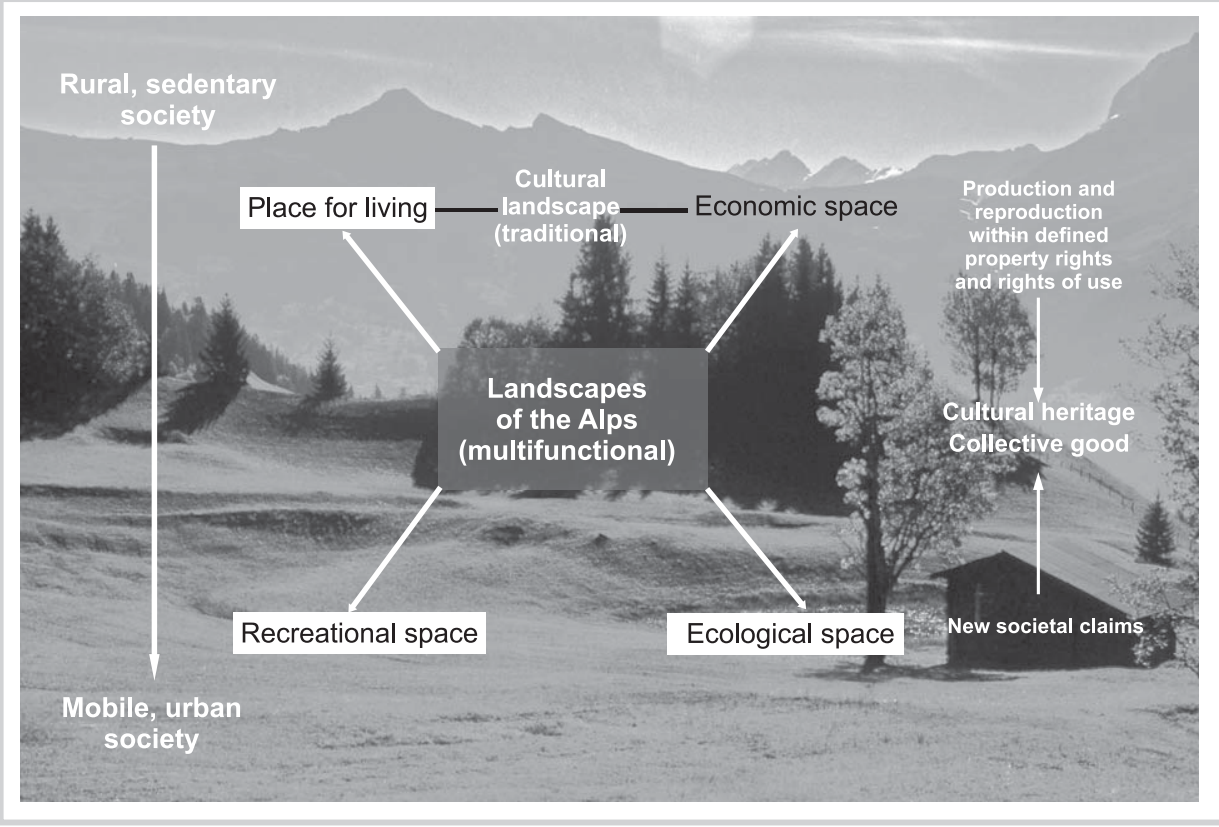

FIGURE 1 Alpine landscapes and changing societal claims over the past 50 years. 
FIGURE 2 The scientific challenge: landscape research as a link between perception, function, and production.

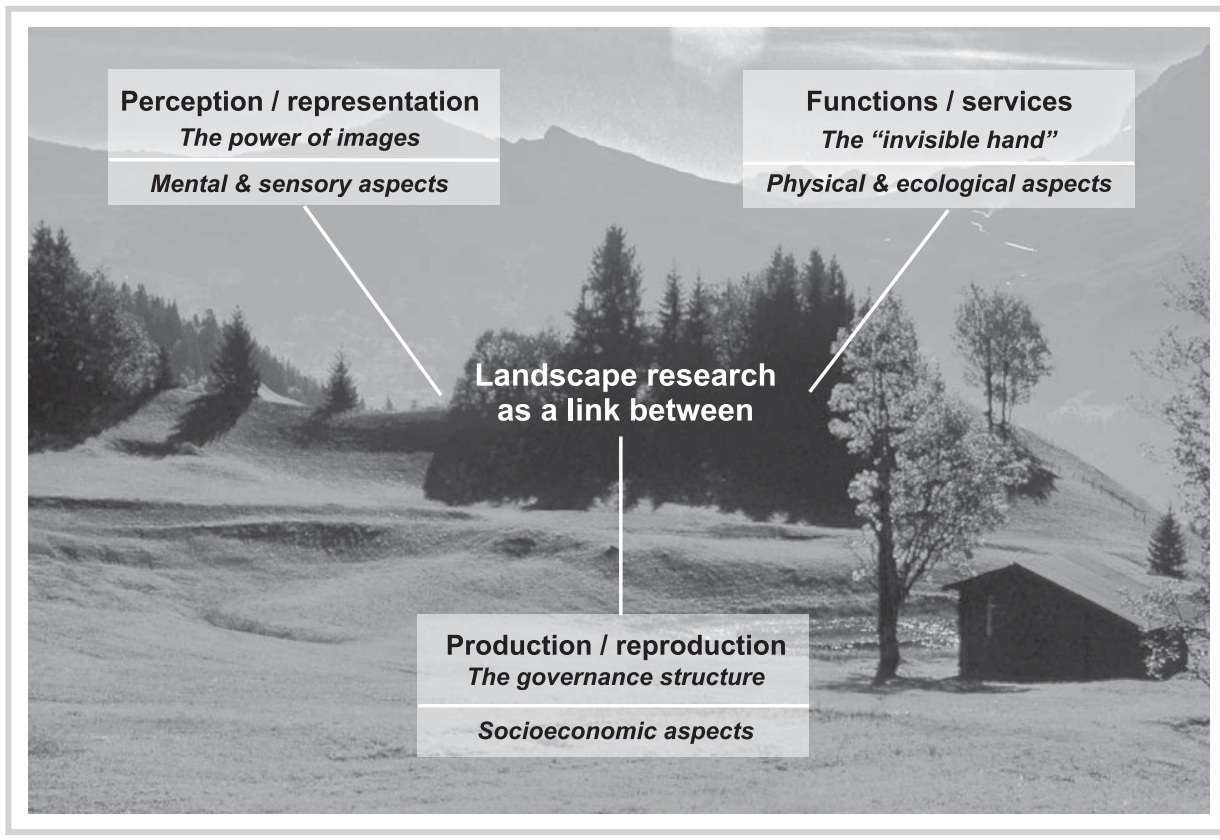

The survival of these local communities depended so much on natural resources that they strove to keep them as reliable as possible.

According to this paradigm, specific institutions and collective behavior were developed to maintain the resources' productive capacity and, if landscape was impaired by natural disasters, to quickly recover these living and economic spaces. Over time, however, rural sedentary societies embedded in the ecological context of their living place became marginal in a modern, mobile and urban society. As a consequence, different perceptions and new value dimensions attributed to the physical environment came into play and entered academic analysis and public discourse.

In the late 1970s UNESCO Man and Biosphere (MAB) research in the Swiss Alps detailed as a major finding the multiple values of the traditional cultural landscapes associated with farming societies, such as sustainable productivity, ecological stability, biodiversity and aesthetic quality (Price 1995). Subsequent research showed that this model was rapidly being challenged by the economic depreciation of primary production (agriculture, forestry) and the associated rapid decline in employment in the primary sector. Not surprisingly, new claims on mountain landscapes were being made by urban communities primarily seeking recreational spaces. As a consequence, traditional farming communities were increasingly losing power over decisions relating to landscape development in mountainous areas. The shaping of Alpine landscapes now also depended on the stakes of external actors, and landscape was conceived of as a collective good with new functions. This led to a major shift in landscape research objectives, from conservation of traditional landscapes (MAB) to negotiation of future landscapes (NRP).

The concurrent increasingly economic focus of thinking in the social sciences led to interpretation of the conflict between farmers' and citizens' interests as an example of a producer-consumer conflict that can be addressed through a series of negotiations. As a result, the term "negotiated landscape" was coined. Figure 1 illustrates this shift of focus from a rather uncontested subsistence logic to a producer-consumer "conflict" dubbed "negotiated landscape."

\section{2) Landscape research as a link between perception, function, and production}

Thus, from the perspective of current research, landscape has a double meaning. On the one hand landscapes are a product of cultural and natural forces in continuous interplay, and together constitute an element of the biophysical world. On the other hand, landscapes are part of the mental world and have an aesthetic dimension and a normative component, which are reflected, among other areas, in the arts (painting, photography, poetry, etc; Figure 2).

The twofold perception of landscape as part of the material/biophysical and the mental worlds has to be taken into account in order to deal with landscape development from the perspective of multiple stakeholders in a potentially conflictual situation as described above.

This dual meaning of the subject implies a multi-, inter- and even transdisciplinary research approach. Humanities and the social and ecological sciences have 


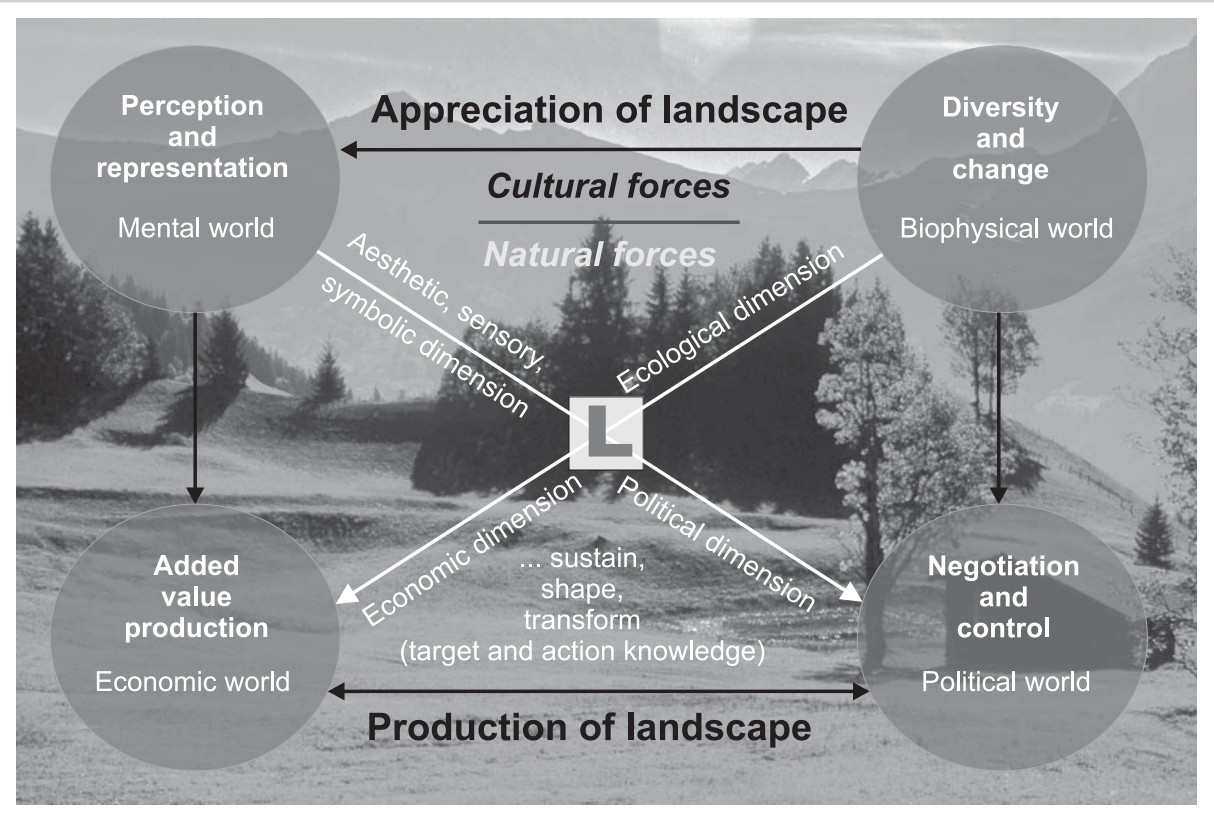

FIGURE 3 Towards demand-driven landscape development: from appreciation to added value production.

to cover the fields of perception and representation (the power of images), the functions and services of landscape ecosystems, and the production and reproduction of landscapes under specific socioeconomic conditions. Landscape research acts as an interface between these different approaches, with a view to integrating knowledge of all relevant dimensions and contributing in this manner to a negotiation process between consumers and producers of landscapes. If these dimensions remain unexplained in a negotiation process-in which a transdisciplinary approach will typically be chosenthe outcome would hardly be satisfactory. In Switzerland, the main purpose of landscape research today is to make landscape development negotiable.

\section{3) Towards demand-driven landscape development}

The step from knowledge to action in landscape research is equivalent to moving from the multifaceted appreciation of landscapes to a framework capable of orchestrating negotiation processes and added value production (Figure 3). In doing this, landscape research today plays a key role in facilitating the transformation from a supply- to a more demand-driven form of landscape development. This shift in development can be realized either by the production of marketable goods and services (organic or regional products, different forms of rural tourism) or by payments for ecosystem services, ie to compensate for restrictions in land use and property rights and support the production of collective goods such as biodiversity and ecosystem services.

However, two major reservations have to be made when this principle is adopted for further landscape development. Irreversible biophysical processes can be introduced either by abandonment of land use or by overexploitation of natural resources and urbanization. This means that the inherent value of landscape may be lost for further development. The second reservation has to do with the articulation of relevant demand. Whose voice is legitimate and will be respected in a certain regional context? This question becomes crucial when thinking of implementing the concept of "negotiated landscapes."

\section{4) Landscape development in the Alps: from solidarity to partnership}

From a policy-oriented perspective, geographically and historically anchored solidarity with mountain regions in Switzerland-which led to an elaborate system of financial support for marginalized regions-is now evolving into a new partnership model between lowland and mountain areas focusing on landscapes as a collective good (Figure 4). Concurrently, the rise of the integrated concept of "sustainability" - encompassing ecological, economic, and social norms-has sparked a new political and scientific discourse on how to regulate and steer socioeconomic development while maintaining ecological potential.

In this context the governance principle has now been widely adopted in Switzerland: this means that besides the legitimate state institutions (governing from above), other civil society institutions are also allowed to be explicitly involved in preparing new regulation regimes. Today participation and negotiation processes are common means by which non-elected stakeholders become included in a solution-finding process: local residents, second-home owners, enterprises, tourists, agriculture, and forestry are now being involved in negotiating a vision of sustainable development for Alpine regions, based on the principle that landscape is a collective good. Experience with this approach to date indicates that it is particularly suitable in complex problem situations, ie when many different stakeholders, controversial interests and asymmetric power relations are 
FIGURE 4 Landscape development in the Alps: from solidarity to partnership.

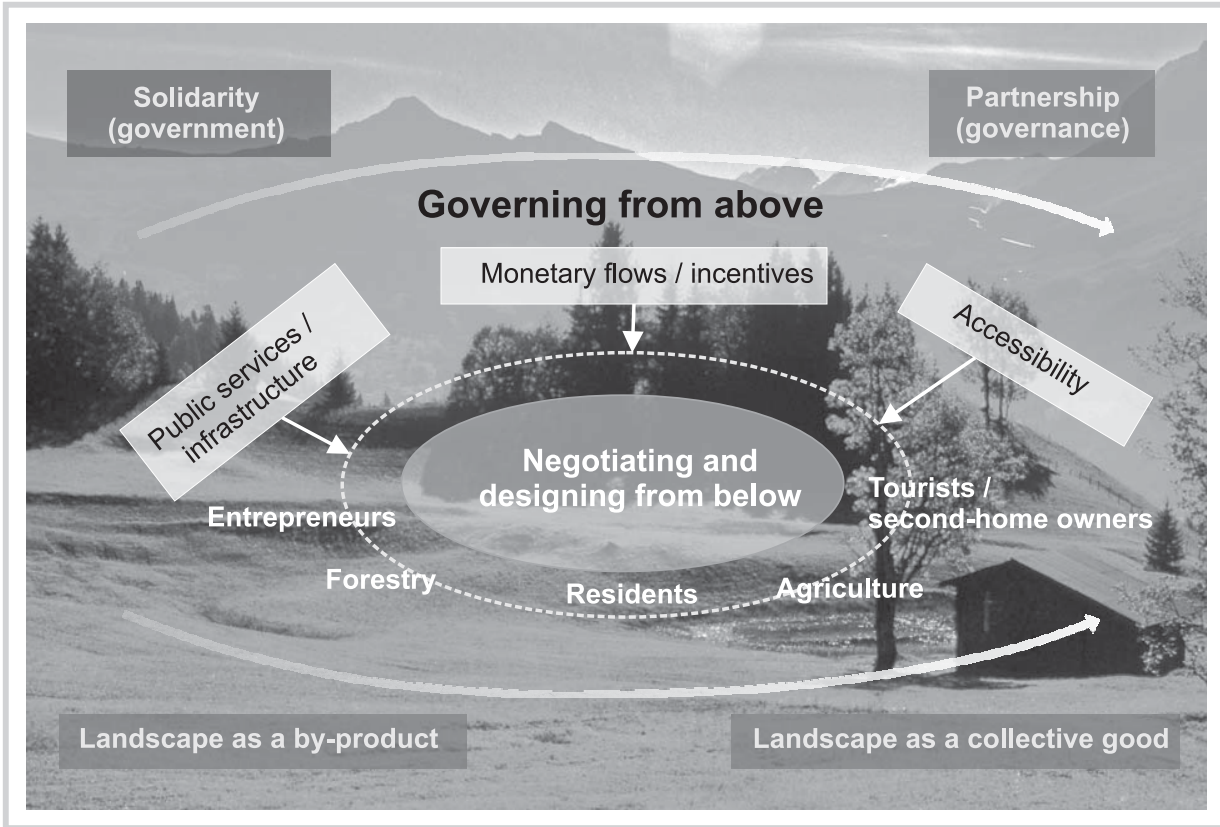

involved, as is often the case between marginalized mountain areas and urban centers.

As shown above, landscape as a by-product of primary production (mainly agriculture and forestry) is nowadays contested by residents, tourists, and taxpayers, who are willing to pay for landscape development according to their own preferences; in addition they want to be involved in the planning process far beyond current practice.

Almost $15 \%$ of the total revenue of the Alpine region of Switzerland is made up of transfer payments, the purpose of which is to offer compensation for natural and topographical disadvantages in mountain areas. These compensation payments almost directly affect land use and also cause land use change. As a major issue, this is becoming a subject of negotiation in a new partnership relation between Alpine and non-Alpine citizens.

The NRP "Landscapes and Habitats of the Alps" not only designed a new framework for landscape research, it also tested new, transdisciplinary approaches with local and regional stakeholders and decision-makers in order to come up with applicable research-based solutions. The papers in the Research section of this special issue of MRD present some of the highlights of the program's results. In the Development section, 5 different approaches are presented, each with its own scope to shed light on how landscape development can be put forward as a collective project in a partnership relation.
- The suggested "branding" of landscapes is a result of negotiation between producers and consumers of landscape as a collective good.

- Negotiating landscape is a general approach to find a compromise between different claims and interests; it requires professional coordination.

- However, a further step is needed: beyond case-bycase solutions, a more sustainable framework such as an "integrated institutional regime" has to be established.

- Monitoring landscape development is a precondition for reflective control of collective actions and shared responsibility.

- Simulating landscapes serves as a form of technological support in a most demanding planning process where visual communication of expected impacts and changes is of great importance.

One of the striking political messages that emerges from the collaborative research conducted within the NRP "Landscapes and Habitats of the Alps" is the following: landscape development is proving to be a major societal concern and-according to our findings-a special challenge for the multilevel Swiss political system. Switzerland has many policies at different levels of decision-making; these need to become part of a new governance regime enabling participation and negotiation on the local and regional levels.

\section{AUTHOR}

Paul Messerli

Institute of Geography, University of Bern, Hallerstrasse 12, 3012 Berne, Switzerland.

mep@giub.unibe.ch

\section{FURTHER READING}

Debarbieux B. 2007. The political meaning of landscape through the lens of Hannah Arendt's human condition. In: Malpas J, editor. The Place of Landscape: Concept, Context, Studies. Cambridge, MA: MIT Press.

Hopf T. 2006. The right of public access to the landscape as a commons situation. GAIA 15(1):16-19.

Pottoff K. 2007. Landscape change as an interface for different approaches in landscape research. Erdkunde 61:54-71.

Price MF. 1995: Mountain Research in Europe. An Overview of MAB Research From the Pyrenees to Siberia. Man and the Biosphere Series. Paris, France: UNESCO [United Nations Educational, Scientific and Cultural Organization]. 